\title{
Service Systems and Systems Sciences in the 21st Century
}

\author{
Jennifer M Wilby \\ Kyoichi Kijima \\ David Ing \\ Gary S. Metcalf \\ University of Hull \\ Tokyo Institute of Technology \\ IBM \\ InterConnections LLC \\ j.wilby@hull.ac.uk, kijima@valdes.titech.ac.jp, daviding@ca.ibm.com, \\ gmetcalf@interconnectionsllc.com \\ Copyright @ 2010 by Jennifer M. Wilby, Kyochi Kijima, David Ing, Gary S. Metcalf. Published and used by INCOSE with permission.
}

\begin{abstract}
Progress on the emerging science of service systems will be advanced by improved collaboration between scientists, engineers, managers and designers. The endorsement of SysML by the OMG provides an option for rigourous descriptions of service systems.

The domains modeled by systems engineers have generally been technical in nature. "A service system can be defined as a dynamic configuration of resources (people, technology, organisations and shared information) that creates and delivers value between the provider and the customer through service" (IfM and IBM 2008). Service systems in the 21st century not only include service machines, but also commercial relationship interactions and public infrastructural and social offerings. Broadening the domains of interest to the subjective and the ambiguous presents challenges not only the formal modeling of systems, but also the effective attainment and communications of shared understandings.
\end{abstract}

A group of senior researchers with shared knowledge in the systems sciences has been conducting conversations about service systems, applying modeling tools in both face-to-face and distributed communications. Findings on joint learning, obstacles, and the responses from observers will be discussed.

\section{Introduction: Jennifer M. Wilby, "Service Systems and the Systems Sciences"}

This panel is to be moderated at the INCOSE International Symposium in Chicago, July 2010, by Jennifer Wilby.

The service economy is calling for the development of T-shaped people, with both depth in specific disciplines and the breadth to bridge the challenges of working across people, technology, organization and shared information. These individuals will be chartered to become "social value architects", with the ability to cross and bridge communities of practice with a wide variety of skills and expertise.

The systems sciences provide a strong foundation on which service systems can be understood. In addition to the technical knowledge typical amongst systems engineers, appreciation for social behaviours in individual and interpersonal interactions rise in importance.

In addition to gaining proficiency across functional specialties, service systems designer will need a greater awareness of issues of implementation, with implications on boundaries, scale, and measurement. These can be informed by the models, methods and theories well developed in the systems sciences. 


\section{Position \#1: Kyoichi Kijima, "A Co-creation Model of the Process of Service Innovation"}

\section{Introduction}

Concept of service is increasingly important not only in practice but also to many academic fields, but from each disciplinary perspective service is viewed somewhat different. For example, social sciences including economics deal with service as a residue out of agriculture and manufacturing. Though they distinguish service as intangibles from agriculture and manufacturing (tangible), they try to measure the growth of service sector in the same terms of agriculture and manufacturing such as number and types of jobs (employment) and number and types of firms.

Service marketing proposes "gaps model of service quality”, a well-known conceptual framework to understand service quality in an organization. According to it, service provider has to close several gaps including a customer gap between customer expectations and perceptions to deliver quality service.

\section{Service as Social Value Co-creation}

We claim that unification of various disciplinary perspectives is possible by defining service as a phenomenon observable in the world in terms of types of entities, interactions and outcomes; in other word, by seeing it as a system. Then, service is defined as social value co-creation interactions among entities like government agencies, not-for- profit organizations, businesses and individuals (Table 1).

Since service science is viewed as a specialization of systems sciences according to Jim Spohrer, we call the approach service systems science. Service systems science is study of social value co-creation phenomena among service system entities. Here, service system is defined as a dynamic interaction of providers, customers, ICT (information and communication technology) and shared information that creates value between the provider and the customer (IfM and IBM 2007).

\section{Co-creation Model of Service Innovation}

Co-creation Model of Service Innovation is developed based on the service system model above in order to shed light its dynamic process of the interactions (Figure 1). It consists of two phases. 


\begin{tabular}{|c|c|c|c|}
\hline \multicolumn{3}{|c|}{ Social Value } & Create \\
\hline \multirow{2}{*}{$\begin{array}{l}\text { Research } \\
\text { Domains }\end{array}$} & \multirow[t]{2}{*}{ Research Aspects } & \multicolumn{2}{|c|}{ Related disciplines } \\
\hline & & Disciplines & Systems Sciences \\
\hline $\begin{array}{l}\text { Basic Value of } \\
\text { Social } \\
\text { Infrastructure }\end{array}$ & $\begin{array}{l}\text { Pandemic Disease, } \\
\text { Terrorism and risk } \\
\text { Management, } \\
\text { Health-care }\end{array}$ & $\begin{array}{l}\text { Social Systems } \\
\text { Theory, Social } \\
\text { Simulation, } \\
\text { Intelligent Systems }\end{array}$ & $\begin{array}{l}\text { Communication } \\
\text { Language: Trans- } \\
\text { disciplinary, Analogy, } \\
\text { Commensurability }\end{array}$ \\
\hline $\begin{array}{l}\text { Innovative } \\
\text { Service Value of } \\
\text { Business }\end{array}$ & $\begin{array}{l}\text { Innovative Business } \\
\text { Models, Service at } \\
\text { NPO }\end{array}$ & $\begin{array}{l}\text { SSME, Leadership } \\
\text { Management }\end{array}$ & $\begin{array}{l}\text { discipline, Systems } \\
\text { thinking, Map of } \\
\text { intellectual }\end{array}$ \\
\hline $\begin{array}{l}\text { Sustainability of } \\
\text { Global } \\
\text { Community }\end{array}$ & $\begin{array}{l}\text { Consensus Building, } \\
\text { Confrontation } \\
\text { Management, } \\
\text { Global Governance }\end{array}$ & $\begin{array}{l}\text { Soft Systems } \\
\text { Thinking, } \\
\text { International } \\
\text { Environment } \\
\text { Politics }\end{array}$ & $\begin{array}{l}\text { Co-creation, Co- } \\
\text { experience, Co- } \\
\text { production }\end{array}$ \\
\hline
\end{tabular}

Figure 1: Social Value, Research Domains, Research Aspects, Related Disciplines

When provider and customer participate in service process, they enter co-experience and co-definition phase, which is most crucial for value co-creation. At this phase, not only provider but also even customer may not know exactly what he/she wants. By co-experience, the provider and customer share internal model to co-define a common understanding about the service. That is, through the interactions provider may understand customer's needs and preference, while customer could recognize provider's direction of service.

Then, social value can be innovated both in terms of co-elevation and co-development interaction between them. The former refers to spiral up mechanism between customer's needs and provider's capability. Higher expectations for service from intelligent and literate individuals define greater social values, driving higher quality service. For example, tagging rice with the identity like names and photo of the producer at the supermarket in Japan is driven by strong desire for quality assurance of the customers.

The latter emphasizes joint collaboration in service innovation. A well-known example is seen in the development and innovation process of Linax system.

In both cases, ICT can play an important role in clarifying the state of the service system and progress towards mutual interests. 


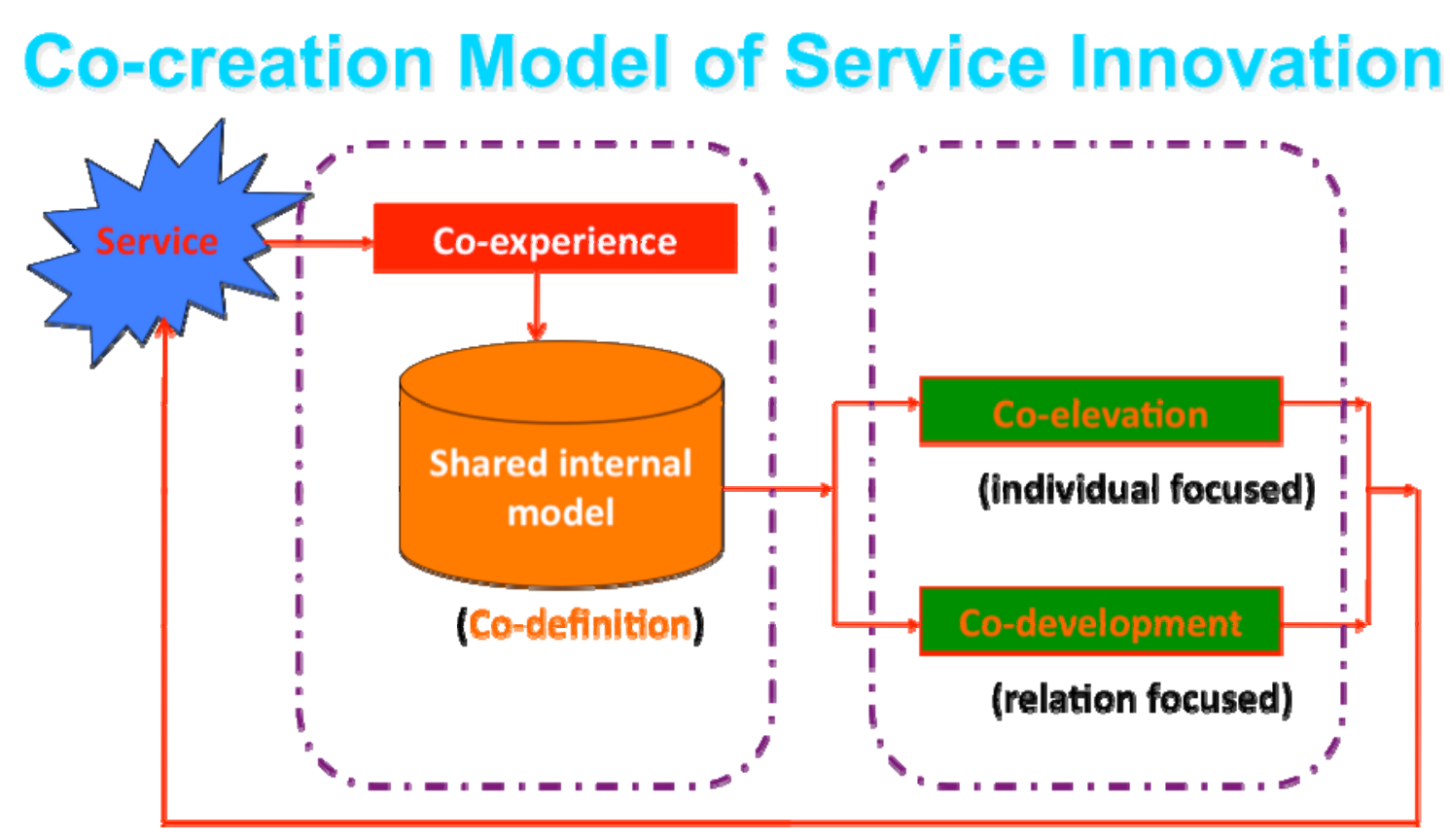

Figure 2: Co-creation Model of Service Innovation

\section{Conclusions}

Co-creation model of service innovation is proposed. The model is characterized by (1) co-experience and co-definition phase, where customer and provider are sharing internal model each other, and (2) co-elevation, spiral up of service quality, and co-development through synergy effect by needs and seeds.

\section{Position \#2: David Ing, "Service Systems, Systems Language, and Modeling Tools"}

In the mid to late $20^{\text {th }}$ century, the communities interested in the systems sciences and in systems engineering often shared dialogues. Names familiar to both worlds include Russell Ackoff, John Warfield, Stafford Beer and Peter Checkland. As time passed, many of the mysteries of the industrial world were resolved, with conventional wisdoms and common practices become "known knowns" that could be published in standard references and textbooks.

The service economy emerging in the early $21^{\text {st }}$ century is still a mystery. The leader of service business recruiting workers with a mindset in the industrial world could have the same issues as an early industrialist recruiting workers with a mindset in the agricultural world (Ing 2010). The challenge of unlearning passive ignorances - errors as things that we believe are true, but aren't are as large as the challenges of learning (Ing, Takala and Simmonds 2003). The disciplinary knowledge based on the industrial paradigm may be leading us astray in economies dominated by service systems.

Systems scientists and systems engineers have the opportunity discover this new world together. The opportunity is described below in four parts:

1. Service systems have parts that are social, physical, social and informatic. 
2. The clarity of language in systems can help bridge science, engineering, management and design.

3. Evolving a systems understanding from the conceptual to the concrete may (or may not) be aided with tools.

4. Service systems can provide at least an initial context in which systems scientists and systems engineers can mutually benefit.

The first step on the collective journey for systems scientists and systems engineers is an engagement in dialogue to appreciate the interests and priorities across their perspectives.

\section{Service systems have parts that are physical, social and informatic}

While mechanical subsystems may be seen as serving other subsystems, a service system as a whole has a purpose to serve human beings. While agricultural and industrial systems larger have human beings working to change the physical world, service systems impact not only physical spaces, but also social spaces and informatic spaces. These impacts change the nature of social interactions (Ing and Simmonds 2002).

Studies on physical systems have been recorded since the dawn of man. The design of social systems has been approached as an art, gradually formalized into principles and relationships appreciated as science. Information systems have been recognized since books were first catalogue in libraries, and then accelerated rapidly with the advent of digital computer technology.

The rapid rise of the Internet since the 1990s, concurrent with trends towards globalization, has made the world smaller. The merging of digital and physical infrastructures - as instrumented, interconnected, and intelligent - into a smarter planet sees systems not only of physical systems, but also of social systems (Palmisano 2008).

In order for these service systems to truly serve human beings, the science and engineering enabling their development should evolve. Systems thinking involves consideration of the containing whole for which the thing to be explained is a part (Ackoff 1981). The models, rules and heuristics developed in the industrial age may not apply in the new service economy.

\section{The clarity of language in systems can help bridge science, engineering, management and design}

Systems language is so commonplace in our daily vocabulary - with similar meaning across a variety of cultures - so that we often don't think about how much knowledge is share. Concepts such as function, structure and process have precise definitions upon which deep reflection is not applied. Working across disciplines and fields, however, increased attention to meaning can be fruitful.

A sample of systems concepts demonstrates how service systems can be discussed with increasing rigour (Ing 2010):

- boundary;

- order, purpose, self-organization;

- living, being, becoming;

- energy, complexity;

- form, networks, power laws; 
- information, communications, meaning;

- coevolution, competition, variety;

- aesthetics, ethics, morals.

In the process of design across a group of interested and involved parties, conversations on desirable and undesirable features in service systems often include these considerations.

The systems engineering literature includes natural and human systems as part of its domain:

[A] system [can be defined as] an assemblage of objects united by some form of regular interaction or interdependence ... A system can be natural (e.g., lake) or built (e.g., government), physical (e.g., space shuttle) or conceptual (e.g., plan), closed (e.g., chemicals in a stationary, closed bottle) or open (e.g., tree), static (e.g., bridge) or dynamic (e.g., human). In regard to its elements, a system can be detailed in terms of its components, composed of people, processes and products; its attributes, composed of the input, process and output characteristics of each component; and its relationships, composed of interactions between components and characteristics. [Tien \& Berg, 2003, pp. 23-24]

Similarly, management - as a multidiscipline - has some who clearly appreciate foundations in the systems sciences.

[Amongst] Management Scientists ... the systems approach to problems is fundamental and ... organizations, a special type of system, are the principal subject of study.

The systems approach to problems focuses on systems taken as a whole, not on their parts taken separately. Such an approach is concerned with total-system performance even when a change in only one or a few of its parts is contemplated because there are some properties of systems that can only be treated adequately from a holistic point of view. These properties derive from the relationship between parts of systems: how the parts interact and fit together. [Ackoff 1971]

Caution should be taken from disciplinary thinkers whose use of the language is limited to their specific domain(s) of interest. The principal aims, at the foundation of the Society of General Systems Research - which evolved to become the International Society for the Systems Sciences were:

- to investigate the isomorphy of concepts, laws, and models in various fields, and to help in useful transfers from one field to another;

- to encourage the development of adequate theoretical models in areas which lack them;

- to eliminate the duplication of theoretical efforts in different fields; and

- to promote the unity of science through improving the communication among specialists.

In developing a new science of service systems, these principal aims can be important again.

\section{Evolving a systems understanding from the conceptual to the concrete may (or may not) be aided with tools}

In the domains in which service systems operate, tools can be interpreted at multiple levels of abstraction. To abstract thinkers, tools can be thought frameworks which assist in structuring concepts and relationships. To practical, hands-on workers, tools are concrete instruments that 
automate routine activities. Bridging from science to engineering raises the opportunity for - and challenges of - common tools.

A concrete example of a set of large scale service systems for redesign has been led in the Municipal Reference Model project led by the Municipal Information Systems Association of Canada (MISA 2008). At the conceptual level, standardization in the definition of programs and services of municipal government services is being pursued, in an interest of comparability of performance levels and budgets. At a practical level, these plans relate to specifications of physical resources (e.g. flows of water) and human resources (e.g. schedules for workers). OMG SysML has been initially adopted as a way to rigourously represent these models.

The average worker does not, however, normally work with modelling tools that create rigourous representations of service systems. At best, sketches and drawings are taken as boundary objects (Bowker and Star, 2000) where sub-communities have been able to converge on a representation even if they do not entirely concur on its meaning. The challenge of developing new flexible modelling tools that will evolve from gradual formalization from simple diagrams to rigourous models is currently a topic for research (Ing, Metcalf and Wilby 2009).

\section{Service systems can provide at least an initial context in which systems scientists and systems engineers can mutually benefit}

The lapse in solidarity between the systems scientists and systems engineers may be attributed to the resolution of many "hard problems" that were jointly faced in the 1970s. The lack of continuity has contributed to the two communities drifting apart, with the richness of knowledge lost through lack of context. The emergence of service systems - with associates sciences and engineering - present a point of convergence on which energies can be combined.

Service systems are not the only context in which the estranged cousins of scientists and engineers can be brought together. The scientists have continued research into the modelling and design of social systems, as well as having advanced knowledge in ecology and natural systems. Engineers have developed tools and methods that have proven workable in a wide variety of applications. Bringing these two communities together is an opportunity not only to regain forgotten knowledge, but also to create new knowledge.

\section{Position \#3: Gary S. Metcalf, "Models and Messes in the Sensemaking on Service Systems"}

There are many arguments around the question of what constitutes an accurate description or depiction of a phenomenon. From the perspective of science, and of many technical disciplines, only descriptions in mathematical terms represent rigor or accuracy. Mathematical formulae and terminology not only require exact definition of terms and concepts, but also reduce the confusion and ambiguity of natural, spoken languages, and the sometimes vague interpretations that result. From this perspective, only models that reach a mathematical level of accuracy are of real value, because only then can they replicate the behavior or functioning of the phenomenon in question, especially in a predictive manner.

A typical counter-argument is that while mathematical models are accurate and useful for many things, most particularly with respect to matter and energy, they fail to capture characteristics which may be equally or more important to a given area of concern. Most particularly in areas 
such as human emotion or experience, criticisms of mathematical or technical models range from them being "sterile" to simply being meaningless.

Research and practice with respect to organizations (e.g. organizational development, organizational behavior, organizational dynamics, organizational systems, etc.) reflects these differences in many ways, and has shown conflicting trends for decades. In terms of human organizations and social systems, the most well-known application of scientific principles is probably Frederick Winslow Taylor's (1916/1992) development of Scientific Management in the early 1900s, which focused on process measurement and optimization. This approach was countered in the US in the early 1930s by the Hawthorne Experiments (Mayo, 1949), which led to the Human Relations movement and its focus on work environments, motivation, etc. In the UK, work at Tavistock combined psychoanalysis with systems principles, dating back to World War I. The same approach was used later in the formation of the National Training Labs (NTL) in the US.

Also prominent by World War II was Operations Research (OR), which relied on strict mathematical algorithms. Beer's (1981) Viable Systems Model, emerging in the same era, was based in mathematics and cybernetics. Forrester's System Dynamics, which relied on computer models, originated from the feedback principles developed for servomechanisms in World War II.

By the 1960s early adherents of OR, including Churchman and Emery (1964) and Ackoff (Systems, messes and interactive planning), rejected a strictly technical approach to human organizations, arguing that concepts such as ethics and purpose were essential in human systems. Their work influenced Checkland (1993), in the UK, a systems engineer who developed Soft Systems Methodology as a way to better incorporate human factors.

So for at least the last hundred years, the arguments have persisted. Should you begin with rigorous methods and models and work to apply those to increasingly complex and ambiguous phenomena, or do you start from an understanding that even the most sophisticated models are still human endeavors, subject to the limitations of human perception and wisdom? Is the goal only absolute accuracy (if that is ever truly possible) and knowledge for its own sake, or is the point really only the usefulness of the knowledge; something that improves the human condition in some way?

Snow (1959) concluded that the different approaches actually described different cultures of people: the literary intellectuals and the scientists. (Snow himself was trained as a scientist, but worked as a writer, so actually lived in both worlds.) The literary intellectuals of the time apparently considered themselves to be the keepers of "high culture." Snow also described them as "natural Luddites." Scientists, on the other hand, showed little interest in literature - even that of Charles Dickens - which so captured much of the human condition. The result was a "gulf of mutual incomprehension."

That same divide may have both increased and fragmented today, with people using and relying increasingly on science and technology, and at the same time not trusting it. Witness, for instance, the public skepticism about climate change, or the desperate desire for new life-saving medical technologies contrasted against the outrage over changes in recommendations for preventive exams (e.g. mammograms.)

Schön (1983) describes the dilemma less as a divide between people, and more as a challenge for practitioners who are often torn between two extremes. As he explains: 
This dilemma of "rigor or relevance" arises more acutely in some areas of practice than others. In the varied topography of professional practice, there is a high, hard ground where practitioners can make effective use of research-based theory and technique and there is a swampy lowland where situations are confusing "messes" incapable of technical solution. The difficulty is that the problems of the high ground, however great their technical interest, are often relatively unimportant to clients or to the larger human society, while in the swamp are the problems of greater human concern (p. 42).

This is not to insinuate, though, that the cultural divide disappears at the level of practice. One argument is that the capabilities of technical solutions are only a matter of time and money for research. Every problem can be solved with enough time and resources. A different argument is that there are limitations to the applications of technology; that tools are only as good as the users. For some people, the application of an accurate model is the answer. For others, even the best model is still only part of a larger human process of decision-making and implementation.

An interesting example can be found in recent modeling work for the US military, as described in a publication by the National Research Council (2008):

Today's military missions have shifted away from force-on-force warfare - fighting nation-states using conventional weapons - toward combating insurgents and terrorist networks in a battlespace in which the attitudes and behaviors of civilian noncombatants may be the primary effects of military actions. These new missions call for agile, indigenously sensitive forces capable of switching quickly and effectively from conventional combat to humanitarian assistance and able to defuse tense situations without, if possible, the use of force. IOS [individual, organizational and societal] models are greatly needed for planning, supporting, and training for these forces and for evaluating the technology with which they fight. Models of human behavior in social units - teams, organizations, cultural and ethnic groups, and societies - are needed to understand, predict, and influence the behavior of these units (p. 2).

The need for such models pushes questions about the interface between human and technical systems to new levels. It is one thing, for instance, to create ever more sophisticated technology for use in existing human systems (in the military, for instance, creating drones to replace manned aircraft.) It is another to create models and technology that affect human interactions and relationships, as noted above. In order to shift the design spaces to ones which might better fit such requirements, it could be helpful to draw from emerging models in governmental services and service science, more broadly.

\section{References}

Ackoff, R. (n.d.) Systems, messes, and interactive planning. Retrieved from http://www.moderntimesworkplace.com/archives/archives.html.

Ackoff, R.L. 1981. Creating the Corporate Future: Plan or Be Planned For. New York: John Wiley and Sons.

Ackoff, R.L. 1971. Towards a System of Systems Concepts. Management Science, Vol. 17, No. 11, July.

Beer, S. 1981. The brain of the firm (2nd ed.). New York: John Wiley \& Sons.

Bowker, GC., and Star, S.L. 2000. Sorting things out. MIT Press. 
Checkland, P. 1993. Systems thinking, systems practice. New York: John Wiley \& Sons.

Churchman, C. W. and Emery, F. 1964. On Various Approaches to the Study of Organizations. Retrieved from http://www.moderntimesworkplace.com/archives/archives.html.

Forrester, J. W. 1989. The beginning of system dynamics. Banquet Talk at the international meeting of the System Dynamics Society, Stuttgart, Germany, July 13, 1989. Retrieved from http://sysdyn.clexchange.org/sdep/papers/D-4165-1.pdf

IfM, and IBM. 2008. Succeeding through Service Innovation: A Service Perspective for Education, Research, Business and Government. Cambridge, UK: University of Cambridge Institute for Manufacturing, 2008. http://www.ifm.eng.cam.ac.uk/ssme/.

Ing, D. 2010. "Service Systems in Changing Paradigms: An Inquiry through the Systems Sciences ", in The Science of Service Systems, (Haluk Demirkan, James C. Spohrer and Vikas Krishna, editors), in the Service Science: Research and Innovations (SRII) in the Service Economy book series, Springer.

Ing, D., Metcalf, G.S. and Wilby, J.M. 2009. Introducing Modeling Tools to Non-Technical Business Professionals: Some Cases with Preliminary Observations, CASCON 2009, http://coevolving.com/blogs/index.php/archive/workshop-on-flexible-modeling-tools-cascon-200 9-markham-on/

Ing, D., Takala, M. and Simmonds, I. 2003, "Anticipating Organizational Competences for Development through the Disclosing of Ignorance", Proceedings of the 47th Annual Meeting of the International Society for the System Sciences at Hersonissos, Crete.

Ing, D. and Simmonds, I. 2002. "Enabling Collective Knowledge Work through the Design of Mediating Spaces: A Framework for Systemic Socio-Informatic Change", Proceedings of the 46th Annual Meeting of the International Society for the System Sciences at Shanghai, People's Republic of China

Mayo, E. 1949. Hawthorne and the Western Electric Company, The Social Problems of an Industrial Civilization, Routledge.

MISA 2008. Pilot Project Being Developed for Municipal Reference Model. September 1, 2008. http://www.misa-asim.ca/en/news/PilotProjectForMunicipalReferenceModel.html

National Research Council 2008. Behavioral modeling and simulation: From individuals to societies. Washington, D.C.: National Academies Press.

Palmisano, S.J. 2008. A Smarter Planet: The Next Leadership Agenda. Council on Foreign Relations, http://www.cfr.org/publication/17697/smarter_planet.html .

Schön, D. A. 1983. The reflective practitioner: How professionals think in action. New York: Basic Books.

Snow, C. P. 1959. The two cultures and the scientific revolution. New York: Cambridge University Press.

Taylor, F. W. 1992. The principles of scientific management. In J. Shafritz \& J. Ott (Eds.), Classics of organization theory (pp. 69-80). Pacific Grove, CA: Brooks/Cole. (Reprinted from Bulletin of the Taylor Society, December, 1916). 
Tien, J. M, and D. Berg. 2003. "A case for service systems engineering.” Journal of Systems Science and Systems Engineering 12, no. 1 (2003): 13-38.

\section{BIOGRAPHIES}

Jennifer Wilby is Director of the Centre for Systems Studies and a lecturer and researcher in management systems and sciences in The Business School, University of Hull. Her research interests include: developing systems resilience and flexibility in the management of complex systems, hierarchies and general system theory, and the development of critical systematic evaluations of research methods. Dr. Wilby is President of the International Society for the Systems Sciences (2010-2011), Honorary Treasurer and executive board member of the Association of Research Centres in the Social Sciences, and a member of the board of the UKSS (United Kingdom Systems Society). She serves at editor of Bulletin of the International Society for the Systems Sciences, editor for book reviews of Systemic Practice and Action Research.

Kyoichi (Jim) Kijima is a professor of Decision Systems Sciences in the Department of Value and Decision Science at the Tokyo Institute of Technology. His current research interests are in decision systems science and service systems science. In the former, he proposes poly-agent systems to deal with complexity in situations consisting of plural and autonomous decision makers or agents. In the latter, he has researched on service systems sciences since 2008, and serves as Director of “Training Program for Design Innovators of Social Service Values,” project endorsed by the Ministry of Education. Kijima-san was vice-leader of the 21st century Center of Excellence Program "Creation of Agent-based Social Systems Sciences", through 2009. As the first Japanese president of the ISSS 2007, he hosted the 51st annual meeting at Tokyo. He has published over sixty refereed papers in high quality international journals, and served as an editor for Systems Research and Behavioral Sciences, Journal of Service Technology and Management, Risk Management, and the Journal of Knowledge and Systems Sciences.

David Ing is a marketing scientist and business architect for IBM, with a legacy of consulting and professional roles over a 25-year career. His research interests are service systems and the systems sciences. David is the vice-president for research and publications of the International Society for the Systems Sciences, having previously served as the vice-president for communications and systems education. He is completing his Ph.D. in industrial engineering and management at the Helsinki University of Technology. He blogs actively at http://coevolving.com .

Gary Metcalf is the president of InterConnections, LLC, a consulting firm based in the U.S. His work focuses primarily on organizational change and leadership. His research interests are in theories of the development and evolution of people, organizations and social systems. Gary is president of the International Federation for Systems Research, and past president (2007-2008) of the International Society for the Systems Sciences. He serves as a part-time faculty member at Saybrook Graduate School and Research Center in San Francisco, California; at the Bhavan Marshall MBA program in Bangalore, India, and at the Federal Executive Institute in Charlottesville, Virginia. 